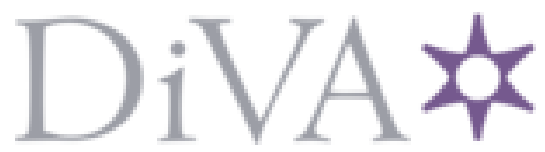

http://www.diva-portal.org

This is the published version of a paper published in Cellulose (London).

Citation for the original published paper (version of record):

Berglund, L., Anugwom, I., Hedenström, M., Aitomäki, Y., Mikkola, J-P. et al. (2017)

Switchable ionic liquids enable efficient nanofibrillation of wood pulp.

Cellulose (London), 24(8): 3265-3279

https://doi.org/10.1007/s10570-017-1354-2

Access to the published version may require subscription.

N.B. When citing this work, cite the original published paper.

Permanent link to this version:

http://urn.kb.se/resolve?urn=urn:nbn:se:umu:diva-137721 


\title{
Switchable ionic liquids enable efficient nanofibrillation of wood pulp
}

\author{
Linn Berglund · Ikenna Anugwom • Mattias Hedenström • Yvonne Aitomäki • \\ Jyri-Pekka Mikkola $\cdot$ Kristiina Oksman $(\mathbb{D}$
}

Received: 23 February 2017 / Accepted: 25 May 2017 / Published online: 6 June 2017

(C) The Author(s) 2017. This article is an open access publication

\begin{abstract}
Use of switchable ionic liquid (SIL) pulp offers an efficient and greener technology to produce nanofibers via ultrafine grinding. In this study, we demonstrate that SIL pulp opens up a mechanically efficient route to the nanofibrillation of wood pulp, thus providing both a low cost and chemically benign route to the production of cellulose nanofibers. The degree of fibrillation during the process was evaluated by viscosity and optical microscopy of SIL treated, bleached SIL treated and a reference pulp. Furthermore, films were prepared from the fibrillated material
\end{abstract}

Electronic supplementary material The online version of this article (doi:10.1007/s10570-017-1354-2) contains supplementary material, which is available to authorized users.

L. Berglund · Y. Aitomäki · K. Oksman ( $₫)$ Division of Materials Science, Composite Center Sweden, Luleå University of Technology, 97187 Luleå, Sweden e-mail: kristiina.oksman@ltu.se

I. Anugwom · M. Hedenström · J.-P. Mikkola Technical Chemistry, Department of Chemistry, Chemical-Biological Centre, Umeå University, Umeå, Sweden

I. Anugwom · J.-P. Mikkola

Laboratory of Industrial Chemistry and Reaction Engineering, Johan Gadolin Process Chemistry Centre, Åbo Akademi University, Turku, Finland

K. Oksman

Fibre and Particle Engineering, University of Oulu, Oulu, Finland for characterization and tensile testing. It was observed that substantially improved mechanical properties were attained as a result of the grinding process, thus signifying nanofibrillation. Both SIL treated and bleached SIL treated pulps were fibrillated into nanofibers with fiber diameters below $15 \mathrm{~nm}$ thus forming networks of hydrophilic nature with an intact crystalline structure. Notably, it was found that the SIL pulp could be fibrillated more efficiently than traditional pulp since nanofibers could be produced with more than $30 \%$ less energy when compared to the reference pulp. Additionally, bleaching reduced the energy demand by further $16 \%$. The study demonstrated that this switchable ionic liquid treatment has considerable potential in the commercial production of nanofibers due to the increased efficiency in fibrillation.

Keywords Switchable ionic liquids (SIL) - Efficient fibrillation - Wood pulp · Cellulose nanofiber .

Ultrafine grinding

\section{Introduction}

The utilization of the cellulose component of wood in various industrial processes would be greatly enhanced by the development of greener approaches to its fractionation. One such approach is the development of greener solvents for the extraction processes, such as deep eutectic solvents (Selkälä et al. 
2016) and ionic liquids (Pang et al. 2016) to mention but a few. 'Traditional' ionic liquids (ILs) are a subclass of molten salts composed of mainly organic cations and inorganic as well as organic anions, and frequently demonstrate melting points below the boiling point of water. More recently many families of more advanced ILs such as 'switchable' ILs have emerged (Anugwom et al. 2014b). Ionic liquids are interesting due to their tunable properties, rendering them suitable as solvents in many applications. Moreover, multitude of ionic liquids has high chemical and thermal stabilities and a wide liquidus range (Wasserscheid and Welton 2006). Several papers can be found in the literature that describes the use of conventional ionic liquids (ILs) in the fractionation of wood. Examples of such ionic liquids include 1-butyl3-methylimidazolium chloride $\left[\mathrm{C}_{4} \mathrm{MIM}\right][\mathrm{Cl}]$, (Swatloski et al. 2002) and 1-ethyl-3-methylimidazolium acetate [ $\left.\mathrm{E}_{2} \mathrm{MIM}\right][\mathrm{OAc}]$, which in ionic liquid-mediated technology, have been reported as powerful when used to produce cellulose nanocrystals directly from wood (Abushammala et al. 2015).

However, the limitations associated with the use of conventional ionic liquids for biomass treatment are high cost, the use of precursors originating from fossil resources, multi-step industrial protocols and ambiguous recycling protocols for many of the formulations. These issues thus rendering them unattractive in large-scale processes. A typical drawback with them is the high viscosity of the wood-IL systems after dissolution, which makes recycling, recovery, and reuse of the ionic liquids less viable. Several recovery methods for ionic liquids used for biomass dissolution have been reported. These methods mainly involve the addition of an anti-solvent. The dissolved material can be precipitated out and the anti-solvent removed from the spent ionic liquid by evaporation (D'Andola et al. 2008; Varanasi et al. 2008). Switchable ionic liquids (SILs), on the other hand, are capable of ionic/non-ionic switching, for example, molecular-to-ionic switching by the addition or removal of a so called "trigger compound" (Anugwom et al. 2011; Jessop et al. 2005). It has been demonstrated in our earlier studies that SILs are potential novel solvents for fractionating lignocellulosic material into its various constituents (Anugwom et al. 2012a; Eta et al. 2014a, b). The power of SILs as solvents for biomass deconstruction was further strengthened when a new protocol, the short time high temperature (STHT) approach (Anugwom et al. 2014b) was carried out for delignification of lignocellulose biomass. The STHT approach was shown to be an efficient way to remove biomass lignin whereupon heavily diluted, aqueous solutions of switchable ionic liquids (SIL) as solvents were used to achieve an impressive delignification efficiency of $95 \mathrm{wt} \%$ (Anugwom et al. 2011). Further, the process was operated at low temperatures with a very short treatment time and at low wood-toionic solvent ratios. The solvent's capacity for biomass deconstruction is the key to increasing process efficiency of the following mechanical processing of the pulp such as in the disintegration of the cellulose fibers to the nanoscale. Ultra-fine grinding techniques have been recognized as the most efficient approach in terms of energy consumed (Spence et al. 2011), and thus has great potential for the commercial, scaled-up production of nanofibers, since reduction of the processing energy is one of the most important prerequisites for industrial production. The aim of this study is to evaluate the use of switchable ionic liquids as a rapid, effective and chemical benign route to producing nanofibers from wood chips using ultrafine grinding.

Firstly, the fibrillation process of SIL treated wood pulp and a bleached SIL treated wood pulp to nanofibers is assessed and compared to that the fibrillation to nanofibers from a reference pulp, in this case a birch Kraft pulp. Secondly, the quality of the nanofibers produced was assessed by a comparison of their characteristics. To assess the fibrillation process, viscosity measurements and optical microscopy (OM) were used during the grinding process and mechanical properties of the films prepared from the fibrillated suspension were tested to evaluate the degree of separation. The energy consumption was also measured during the grinding process. The quality assessment of the nanofibers comprised of a study of the nuclear magnetic resonance spectroscopy (NMR) of the pulps before and after the treatment; the crystallinity of the materials before and after the fibrillation; the water contact angle and surface roughness the wood nanofiber films and the size distribution of the nanofibers characterized using atomic force microscope (AFM). Further to this, a chemical composition of the ionic liquid, $\mathrm{SO}_{2}$ switched DBU MEASIL derived birch pulp was studied before and after the treatment. 


\section{Experimental section}

Materials

Hardwood birch (Betula pendula) in the form of chips was used as raw material for production of nanofibers and was provided by the Natural Resources Institute Finland, (Luke). The reference material was a commercial birch Kraft pulp provided by SCA (Munksund, SE). Used, as received, were the SIL precursors, 1,8-diazabicyclo-[5.4.0]-undec-7-ene (DBU， 99\%) and monoethanol amine (MEA, 99\%) from Sigma Aldrich and the $\mathrm{SO}_{2}(99.998 \%, \mathrm{H} 2 \mathrm{O}<3 \mathrm{ppm})$ provided by AGA Oy (Linde group, Finland). The isopropyl alcohol (2-propanol) (Merck, 99\%, USA) that was applied as the anti-solvent and for washing of the fractions. This was also used as received.

Synthesis of the switchable ionic liquid

The SIL ( $\mathrm{SO}_{2}$ switched DBU MEASIL) was prepared from DBU, MEA, and $\mathrm{SO}_{2}$ by methods described previously in detail (Anugwom et al. 2011; Jessop et al. 2005). An equimolar mixture of DBU and MEA was added into a three-necked flask and the flask was placed in a cooling bath to control the temperature as an exothermic reaction occurs upon the addition of the acidic gas. After that, $\mathrm{SO}_{2}$ was bubbled through the mixture under rigorous stirring. The reaction in the mixture was allowed to proceed freely upon sparging until the formation of the SIL was completed, (Fig. 1). After this, the SIL was kept in a freezer to prevent its decomposition until it was needed. The molar ratio of the amidine (DBU) to hydroxyl containing compound (MEA) was determined based on the number of hydroxyl groups in the alcohol/hydroxyl-containing compound.
Ionic liquid treatment of woody biomass in a nonstirred batch reactor

A $300 \mathrm{ml}$ capacity batch autoclave (Parr Inc., USA) with an electric heater and an internal thermocouple was used in this study. $50 \mathrm{~g}$ of birch chips (approx. $2.3 \mathrm{~cm} \times 8 \mathrm{~cm}$ ), together with $250 \mathrm{~g}$ of $\mathrm{SO}_{2}$ switched DBU MEASIL and $150 \mathrm{ml}$ of water were placed into the reactor to give a weight ratio of 1:5:3 of wood: $\mathrm{SO}_{2}$ DBU MEASIL: water. This was heated to $160{ }^{\circ} \mathrm{C}$ (433 K) for $2 \mathrm{~h}$. No stirring was employed in order to avoid mechanical fibrillation of the chips during the treatment and consequent a low mixture viscosity could be maintained thus facilitating washing. It should also be mentioned that our earlier studies have shown that the process works well even in the absence of stirring. Upon completion of the treatment, the treated wood was subject to washing with a mixture of propanol and water until no visual evidence of the SIL could be found remaining in the solid fraction. This was further verified by testing for traces of sulphate ion in the filtrate using 10 vol\% barium chloride. The SIL pulp samples were subsequently bleached and used for cellulose nanofiber production or used directly without bleaching. In neither case were the samples dried before use.

Bleaching procedure

Bleaching of the SIL treated biomass was performed using acid chlorite bleaching following a previously described procedure by Anugwom et al. (2014a). Briefly a sample of $1 \mathrm{~g}$ was bleached with $0.8 \mathrm{~g}$ $\mathrm{NaClO}_{2}$ and $0.16 \mathrm{~g} \mathrm{AcOH}$ in $40 \mathrm{ml}$ water, at $75^{\circ} \mathrm{C}$ for $2 \mathrm{~h}$ and the chemicals were added in two portions.

Fig. 1 Synthesis of DBUMEASO $_{2}$ SIL. Adapted from Anugwom et al. (2014a)

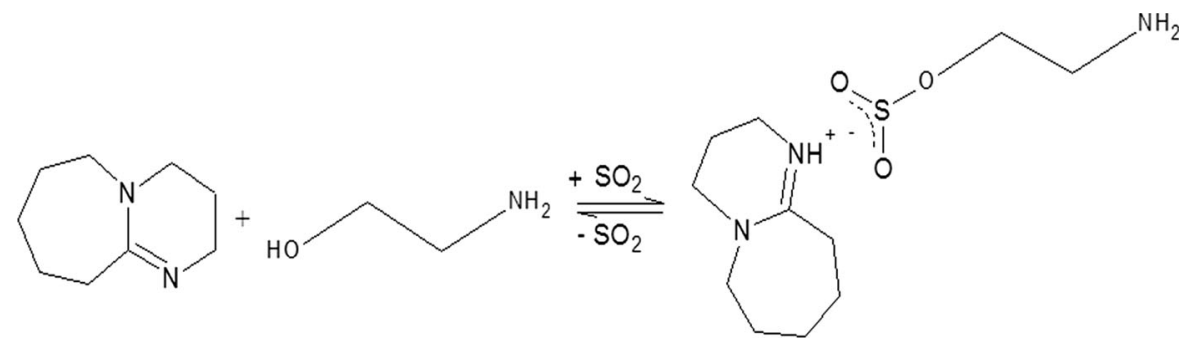


Fibrillation process

The SIL treated pulp was diluted to $2 \mathrm{wt} \%$ concentration, and the bleached SIL pulp and reference pulp were diluted to $1.5 \mathrm{wt} \%$ solids respectively, before the fibrillation. Prior to grinding, the suspensions were dispersed using a shear mixer Silverson L4RT, (Silverson Machine Ltd., England). The materials were processed using an MKCA6-3 Supermasscolloider ultrafine friction grinder (Masuko Sangyo Co. Japan), see Fig. 2. Coarse silica carbide (SiC), nonporous standard stones for soft materials were used in the grinding. The grinding was operated in contact mode with a gap between the two disks set to $-60 \mu \mathrm{m}$, at $1500 \mathrm{rpm}$, for the initial fibrillation stage, and further adjusted to $-90 \mu \mathrm{m}$, for the remainder of the grinding process.

The SIL treated pulp was ground for a total duration of $150 \mathrm{~min}$, compared to the bleached SIL pulp, which was processed for $70 \mathrm{~min}$. The processing time in case

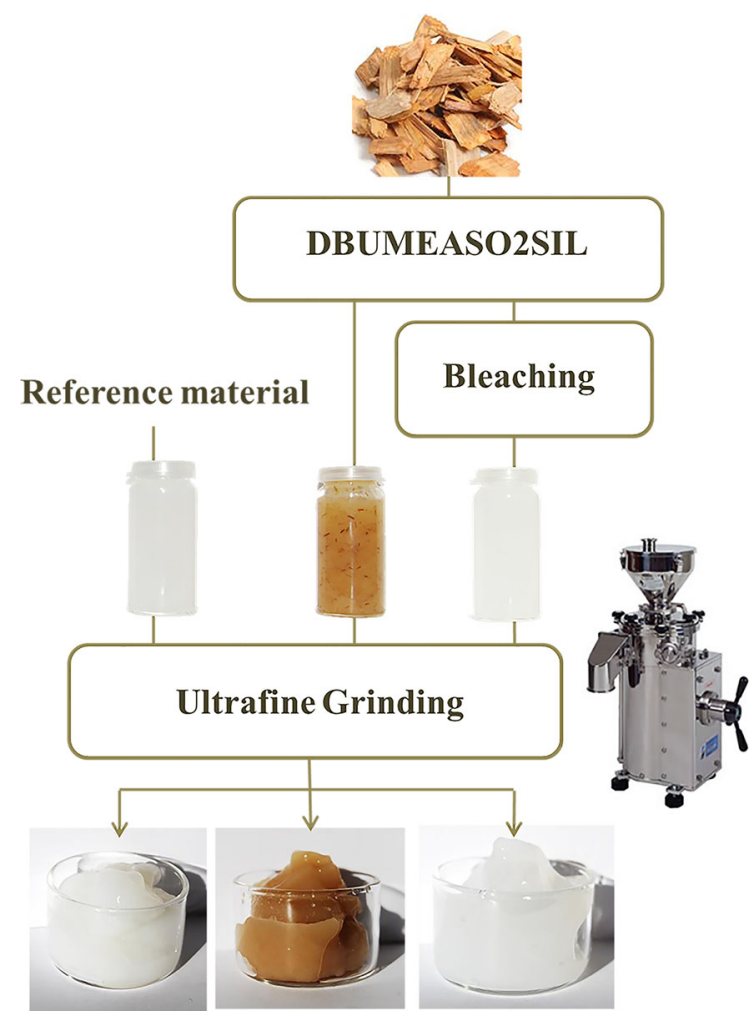

Fig. 2 Diagram and visual appearance of the materials during the process starting from birch wood chips to final SIL treated wood nanofiber gels. The diagram includes the reference material of the reference pulp was $100 \mathrm{~min}$. The energy consumption for the grinding process was established on the direct measurement of power using a power meter, Carlo Gavazzi, EM24 DIN (Italy) and the processing time. The energy demand was calculated from the product of power and time and expressed as MWh per dry weight ton of the nanofibers.

The samples were collected at regular intervals during the fibrillation process and characterized by viscosity measurements together with the optical microscope in order to assess the degree of fibrillation. The grinding process was stopped when a plateau in viscosity was reached and no larger structures could be observed by polarized microscope.

Preparation of films

Films containing various degrees of mechanical disintegration were prepared to assess the degree of fibrillation. After the grinding, the suspensions were adjusted to $0.2 \mathrm{wt} \%$ concentration and dispersed with a shear mixer, IKA T25, UltraTurrax, (IKA-Werke $\mathrm{GmbH} \&$ Co., Germany), operated at 10,000 rpm for $10 \mathrm{~min}$. The suspensions were then degassed and subsequently filtered with a membrane filter; pore size $0.45 \mu \mathrm{m}$, with a glass filter support. The wet cakes obtained were dried by hot pressing at $85{ }^{\circ} \mathrm{C}$, using Fortune presses, LP300, (Fontijne Grotnes, The Netherlands), under $30 \mathrm{kPa}$ for $40 \mathrm{~min}$.

Characterization

Chemical analysis: cellulose and hemicellulose content The carbohydrate content of the samples was analyzed by gas chromatography (GC) after acid methanolysis, followed by silylation and acid hydrolysis followed by silylation to determine the hemicellulose and cellulose content of the sample, respectively (Sundberg et al. 1996; Willför et al. 2005; Anugwom et al. 2012b). For GC analysis, approximately $2 \mu \mathrm{l}$ of the silylated sample was injected through a split injector $\left(260{ }^{\circ} \mathrm{C}\right.$, split ratio 1:5) into a capillary column coated with dimethyl polysiloxane (HP-1, Hewlett Packard). The column length, internal diameter and film thickness were $30 \mathrm{~m}, 320$ and $0.17 \mu \mathrm{m}$, respectively. The temperature program applied was a $4{ }^{\circ} \mathrm{C} / \mathrm{min}$ ramp from 100 to $175^{\circ} \mathrm{C}$ followed by $12{ }^{\circ} \mathrm{C} / \mathrm{min}$ ramp from 175 to $290{ }^{\circ} \mathrm{C}$. The detector (FID) temperature was $290{ }^{\circ} \mathrm{C}$ 
and hydrogen was used as the carrier gas. GC-MS (mass spectrometry) was used to identify the different peaks prior to the GC analysis.

Lignin content determination The lignin content was determined using a modified method similar to the Klason lignin method but in which an autoclave treatment at $125^{\circ} \mathrm{C}$ and 1.4 bar for $90 \mathrm{~min}$ is used to complete hydrolysis of polysaccharides instead of boiling for $4 \mathrm{~h}$ (Anugwom et al. 2012a; Schwanninger and Hinterstoisser 2002).

Nuclear magnetic resonance spectroscopy $(N M R) \quad{ }^{13} \mathrm{C}$ cross-polarization magic angle spinning (CP/MAS) experiments were performed on a Bruker $500 \mathrm{MHz}$ Avance III spectrometer operating at a ${ }^{13} \mathrm{C}$ frequency of $125.75 \mathrm{MHz}$ and equipped with a $4 \mathrm{~mm}$ MAS probe. The SIL treated- and the reference pulp were analyzed as non-dried pulp but due to the high water content, the bleached SIL pulp was air-dried before analysis. $1 \mathrm{~ms}$ contact time was used and 4096 scans were collected for each sample at a spin rate of $10 \mathrm{kHz}$. The spectral data was processed with Topspin 3.2 software (Bruker Biospin, Germany) using a Gaussian window function. All spectra were recorded at ambient temperature.

Optical microscopy $(O M)$ The lateral dimensions of the raw materials, before the grinding process, were measured using a polarizing microscope, Nikon Eclipse LV100N POL (Japan) and the imaging software NIS-Elements D 4.30. The average values reported are based on 60 measurements of different fibers. The microstructure was also evaluated during the mechanical disintegration process.

Viscosity Viscosity measurements were performed during the grinding using a Vibro Viscometer SV-10, (A\&D Company, Ltd, Japan), at a constant shear rate. The velocity (shear rate) of the sensor plates is periodic and based on a sine-wave vibration with a frequency of $30 \mathrm{~Hz}$ and amplitude of $<1 \mathrm{~mm}$. The viscosity measurements were repeated once the temperature of the samples had been stabilized to $22.7 \pm 1.0{ }^{\circ} \mathrm{C}$ to confirm that a plateau in viscosity had been reached during fibrillation. The presented values are an average of three measurements for each sample, where the samples were stirred between the measurements.

Atomic force microscopy (AFM) The nanostructure was studied after the mechanical fibrillation for all samples using an Atomic Force Microscopy. The fibrillated sample suspension $(0.01 \mathrm{wt} \%)$ was dispersed and deposited by spin coating onto a mica plate for imaging. The measurements were performed on a Veeco Multimode Scanning Probe, USA in tapping mode, with a tip model TESPA [antimony (n) doped Si], Bruker, USA. The nanofiber size (width) was measured from the height images using the Nanoscope $\mathrm{V}$ software and the size distribution presented are based on 40 different measurements for each sample. The size distributions were obtained by drawing a line across the height image and subsequently measuring all isolated nanofibers alongside this line. The procedure was repeated for several captured height images until 40 measurements were collected. AFM was also used for characterization of topographical features of the nanofiber films. The root-mean square roughness RMS values were measured from the height images. The images were flattened before the measurements to delete low frequency noise and remove tilt; no other image processing was performed. The values reported are the average of five different measurements on the surface area of $25 \mu^{2}$. All measurements were conducted in air at room temperature.

Density and porosity The density of the films was calculated by determining the weight, area, and thickness of the dried network. The weight was determined using an analytic balance, and the thickness was the average of ten different measurements at different locations measured with a micrometer gauge. The porosity, $P$, was estimated from the density of the dried cellulose network, $\rho_{b}$, by assuming that the density of the nanofiber is $\rho_{f}=1.5 \mathrm{~g} / \mathrm{cm}^{3}$ (Eichhorn et al. 2010), such that:

$\mathrm{P}=1-\left[\rho_{b} / \rho_{f}\right]$

Scanning electron microscopy (SEM) The morphologies of the films fracture surfaces were studied by SEM, JEOL, and JSM-IT300LV (USA) at an acceleration voltage of $10 \mathrm{kV}$. The samples were coated prior to the scanning using Bal-Tec MED 020 Coating system with a tungsten target to avoid charging.

Mechanical properties The mechanical properties of the films networks structures, isolated after different processing times, were tested to provide an indication of the degree of fibrillation. Film samples cut to 
$40 \mathrm{~mm}$ in length and $5 \mathrm{~mm}$ in width were attached to paper frames to facilitate the mounting in the tensile machine. The tests were conducted using universal tensile testing equipment; AG X, (Shimadzu, Japan) equipped with $1 \mathrm{kN}$ load cell. The tests were conducted at extension rate of $2 \mathrm{~mm} / \mathrm{min}$ and the gauge length used was about $20 \mathrm{~mm}$. Prior to experiments, all the samples were conditioned at $50 \pm 2.0 \%$ relative humidity at $23 \pm 1.0^{\circ} \mathrm{C}$ for at least $24 \mathrm{~h}$. The results are the average of at least eight sets of measurements.

$X$-ray diffraction (XRD) The diffraction patterns were obtained using XRD technique and the instrument used was a PANalytical Empyrean X-ray diffractometer (The Netherlands) equipped with a PIXcel $^{3 \mathrm{D}}$ detector and $\mathrm{Cu} \mathrm{Ka}$ radiation $(\lambda=$ $0.154 \mathrm{~nm})$. The $\mathrm{X}$-ray generator was operating at $45 \mathrm{kV}$ and $40 \mathrm{ma}$, respectively. The crystallinity index (CI) was calculated based on the Segal empirical method (Segal et al. 1959):

$\mathrm{CI}=\left[\left(\mathrm{I}_{200}-\mathrm{I}_{\mathrm{am}}\right) / \mathrm{I}_{200}\right] \times 100$

where $I_{200}$ is the intensity of the crystalline peak and $\mathrm{I}_{\mathrm{am}}$ refers to the intensity of the amorphous peak. A baseline correction based on Sonneveld and Visser (1975) was used.

Contact angle measurements The water contact angle of the nanofibers films was measured using an EASYDROP contact angle measuring system with drop shape analysis DSA1 control and evaluation software (Krüss, Germany). A $4 \mu \mathrm{l}$ drop of water was placed onto the sample and the software of the instrument calculated the contact angle over time with a sessile drop technique; the contact angle was determined immediately after a stable drop was formed on the sample surface and used for comparison of the nanofiber networks. The reported values are the average based on five measurements.

\section{Results and discussion}

Chemical composition of the DBUMEASO $\mathrm{DSIL}_{2}$ treated materials

After the SIL treatment using the Short Time-High temperature (STHT) approach (Anugwom et al. $2014 \mathrm{~b}$ ), a $\sim 40 \mathrm{wt} \%$ reduction of the original weight was recorded after washing. The bleached and unbleached woody material after the SIL treatment was subjected to chemical analysis to determine its lignin, cellulose and hemicellulose contents, respectively. The result of the chemical analysis is given in Online Resource 1, together with the results for the reference pulp. The SIL treatment reduced the lignin content by $91 \mathrm{wt} \%$ compared to the total amount in the untreated wood, resulting in marginally lower lignin content than the reference pulp. The bleaching cycle further reduced the lignin content of the SIL treated wood to less than $2 \mathrm{wt} \%$, thus half that of the lignin content of the SIL treated- and reference pulp. As shown previously, the SIL used was selective towards lignin dissolution (Anugwom et al. 2012a). The results of removal of hemicelluloses were similar in both the SIL treated- and the reference pulp. Bleaching combined with the SIL treatment further decreased the hemicellulose content (see Online Resource 1). In addition, the SIL treatment successfully removed over $90 \mathrm{wt} \%$ of the pectins and uronic acids from the wood.

Nuclear magnetic resonance spectroscopy (NMR) analysis

${ }^{13} \mathrm{C}$ CP/MAS NMR spectra of SIL treated and bleached SIL pulps were compared to the reference pulp to further elucidate the effect of the SIL treatment on the woody material. Signals from cellulose appear in the region between 60 and 110 ppm, annotated $\mathrm{C} 1-$ $\mathrm{C} 6$ in Fig. 3. The signal at $89 \mathrm{ppm}$ originates from C-4 of the highly ordered cellulose of the crystallite interiors while the broader up-field signal at $84 \mathrm{ppm}$ is assigned to the C-4 of disordered cellulose (Larsson et al. 1999).

Lignin peaks usually appear in the region of 125-160 ppm with the exception of the methoxyl peak, which is located at $56 \mathrm{ppm}$. Signals from hemicelluloses overlap to a large extent with the cellulose peaks but presence of hemicellulose can be observed as a hump on the up-field side of the $\mathrm{C} 1$ peak from cellulose (Liitiä et al. 2003). Comparing the peak intensities of the different materials, it is clear that only small amounts of lignin and hemicellulose fractions are present, leaving only the cellulose peaks as the dominating features of the spectra (Fig. 3).

These results confirm the results from chemical analysis showing the SIL treated and bleached SIL contain minor amounts of hemicellulose. In addition, 
Fig. $3{ }^{13} \mathrm{C} \mathrm{CP} / \mathrm{MAS}$ spectra of SIL treated pulp, bleached SIL pulp and the reference

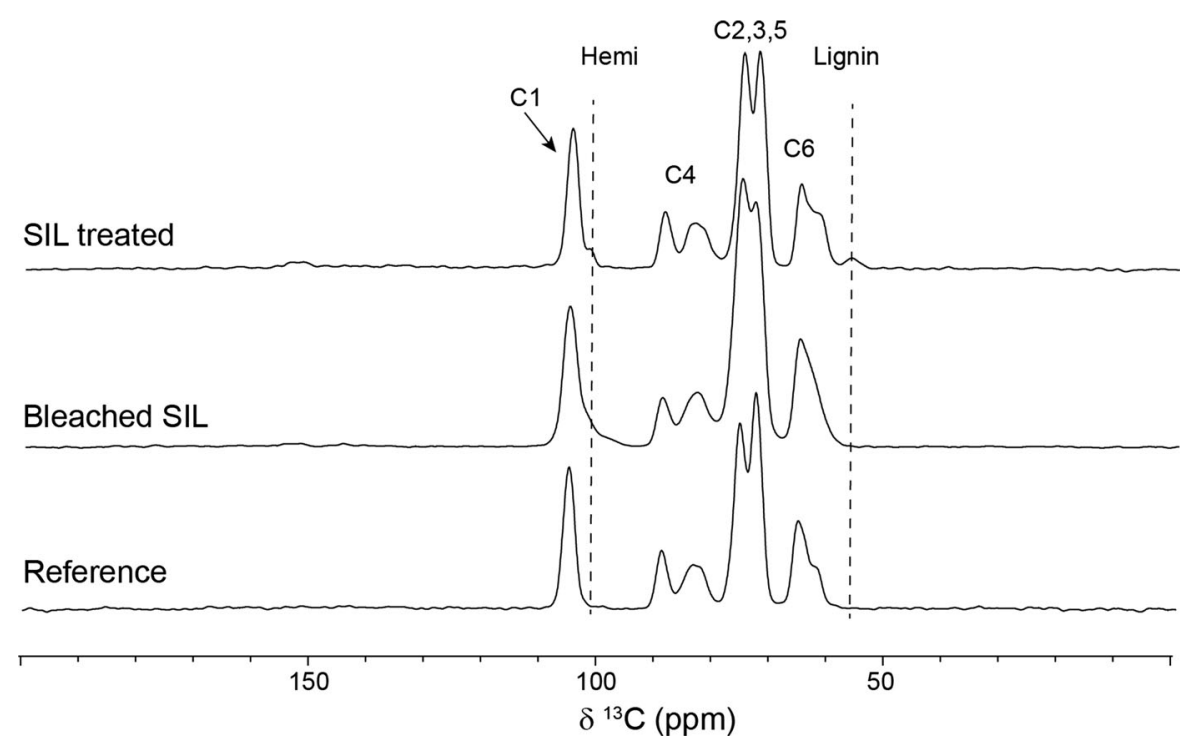

it is evident that the lignin still present after the SIL treatment gives rise to methoxyl resonances, which are no longer present after the subsequent bleaching process confirming the reduction in lignin. The presence of lignin in the reference material is not clearly seen in the spectra possibly reflecting the accuracy of NMR in detecting low lignin levels.

\section{Microstructure}

The optical micrographs of the samples obtained before and during the fibrillation at different processing times in the ultrafine grinder are presented in Fig. 4. The raw materials size was measured for the wood pulps prior to the mechanical disintegration. The Fig. 4 depicts that the SIL treated material appears as larger bundles and had an average width of $89 \pm 27 \mu \mathrm{m}$ and that the bleaching treatment resulted in decreased dimensions to around $31 \pm 9 \mu \mathrm{m}$, which is similar to the reference material at $27 \pm 7 \mu \mathrm{m}$. The larger initial size of the SIL material is likely to be due to the fact that the SIL treatment was carried out in the absence of any stirring whereas the reference pulp was subjected to considerable shearing forces during the industrial bleaching process. The subsequent bleaching of the material also involves a stirring albeit with relatively low shear forces. As intended, the grinding process further reduced the size of fibers to the nanoscale in all pulps but with considerable differences in the time taken depending on the raw material and its treatment. No intact fibers were observed after the grinding, though remaining fragments from the cell wall structure could be seen.

The larger woody structures observed for the SIL treated unground material appeared to require further a processing time of approximately $40 \mathrm{~min}$ to separate them before internal fibrillation could be initiated. However, in the bleached SIL, the initiation of internal fibrillation appeared much earlier and fibrillation was observed at the fiber ends after only $20 \mathrm{~min}$ of processing. After $40 \mathrm{~min}$, comprehensive disintegration was observed for the bleached SIL. At $40 \mathrm{~min}$, the reference material appears be at further stage of the disintegration than the SIL but not as advanced as the bleached SIL material.

The more rapid fibrillation for the bleached SIL pulp could be attributed to the combination of initially smaller fiber dimensions and lower lignin content. For the SIL treated and reference, the lignin may act to maintain the structural integrity of the fiber, thus resulting in a more gradual disintegration process, compared to the bleached SIL.

Atomic force microscopy (AFM) was used for characterizing the nanoscaled material after the grinding process. The captured phase and height images are shown together with the size distribution based on measurements from the height images in Fig. 5.

The AFM confirmed that the fibril dimensions were decreased from micro- to nanoscale upon the grinding process, though bundles of wood nanofibers also were 

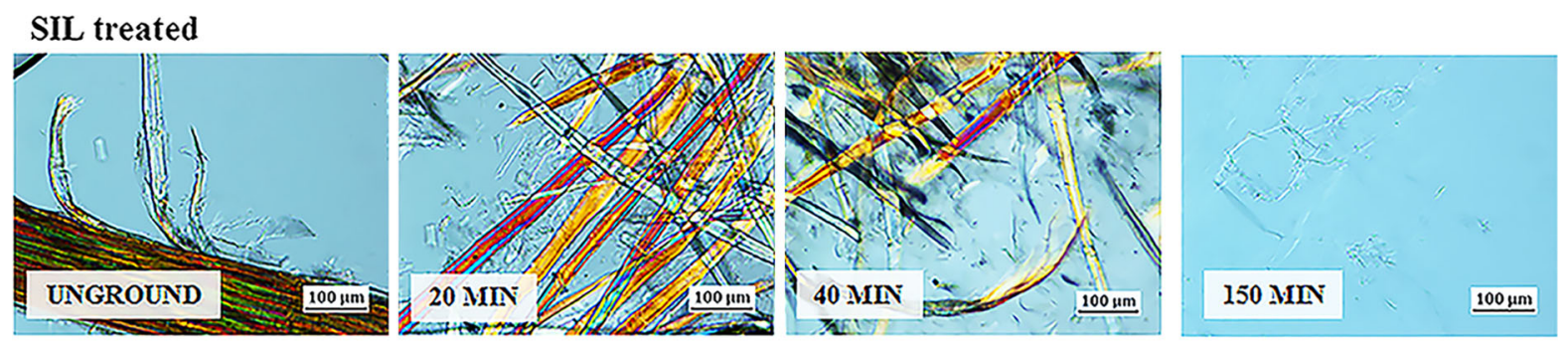

Bleached SIL
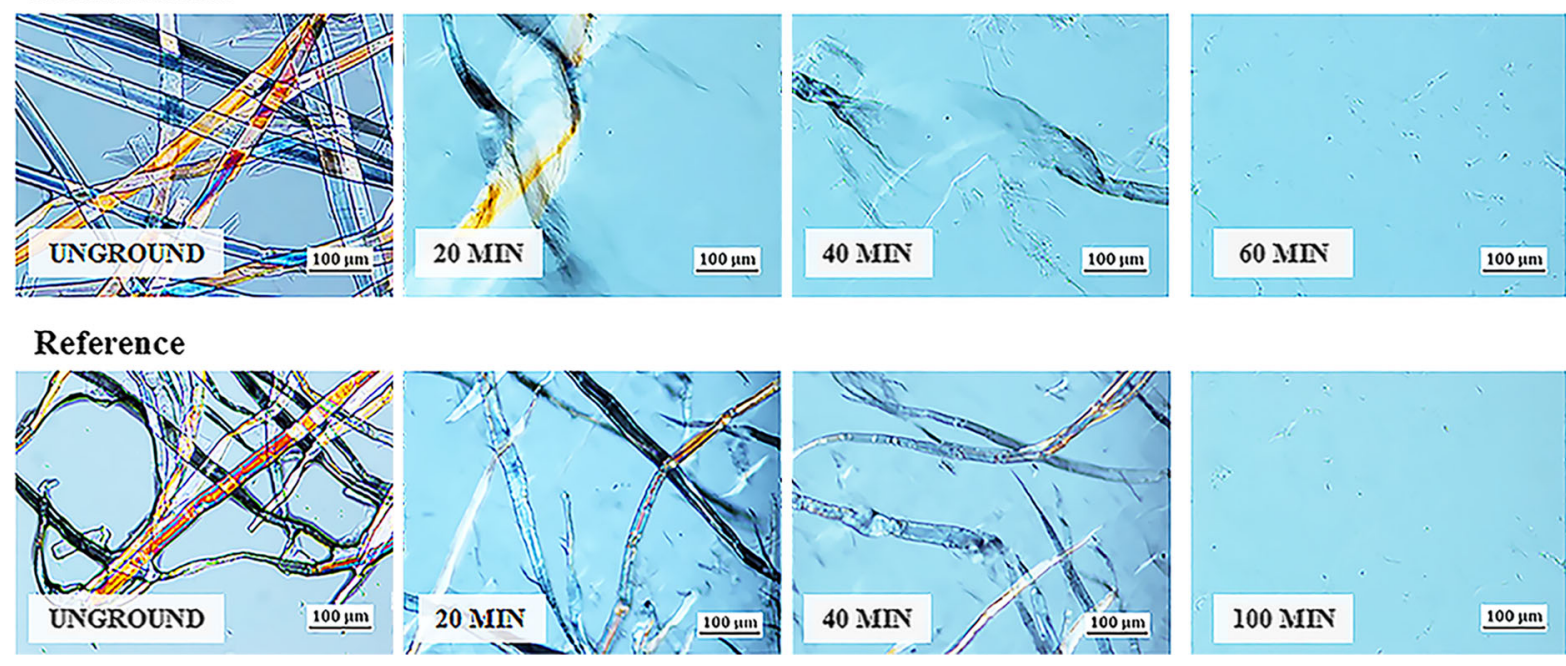

Fig. 4 Fibrillation process of SIL treated pulp, bleached SIL pulp and reference pulp shown with optical microscopy images obtained at different mechanical processing times

observed in all materials. The height measurements of the isolated nanofibers was used to measure the widths of the nanofibers and had averaged values of $15 \pm 8 \mathrm{~nm}$ for the SIL treated nanofibers, $12 \pm 6 \mathrm{~nm}$ for the bleached SIL, and in case of the reference $14 \pm 6 \mathrm{~nm}$ was measured. Thus, no significant differences could be confirmed in the size of the nanofibers in the final nanofiber gels when inspected on this scale and it can be tentatively concluded that the different processing routes and resulting different chemical composition appeared to have minor, if any effect on the nanofiber sizes. However, it should be noted that in AFM measurement, the field of is view visualized is restricted and thus larger structures are often overlooked (Chinga-Carrasco 2013).

\section{Viscosity}

Figure 6 shows the measured viscosity during the grinding process from samples taken every ten minutes and carried out until a plateau in the viscosity was reached. The viscosity is shown as function of the energy consumption during the fibrillation process.

The viscosity of the suspensions increased significantly during the mechanical separation and a gel formation was observed. This increase in viscosity is due to the fibrillation process leading to a greater exposure of the surface area of swollen fibrils, promoting more fibril-to-fibril bonding and this, in turn, implies a higher degree of fibrillation. The apparent increase in the viscosity with the progress of the fibrillation process could be seen of all pulps and has been previously reported for grinding of different wood pulps (Lahtinen et al. 2014). The viscosity increase in case of the bleached SIL pulp occurs almost immediately. The gradient is substantially lower for the SIL treated and reference pulp, yet the reference shows the highest maximum viscosity value. The lower gradient observed for the SIL treated pulp despite the fact that the concentration was in fact higher for this pulp. This is best explained by the breakdown of larger structures before gel formation was induced. 

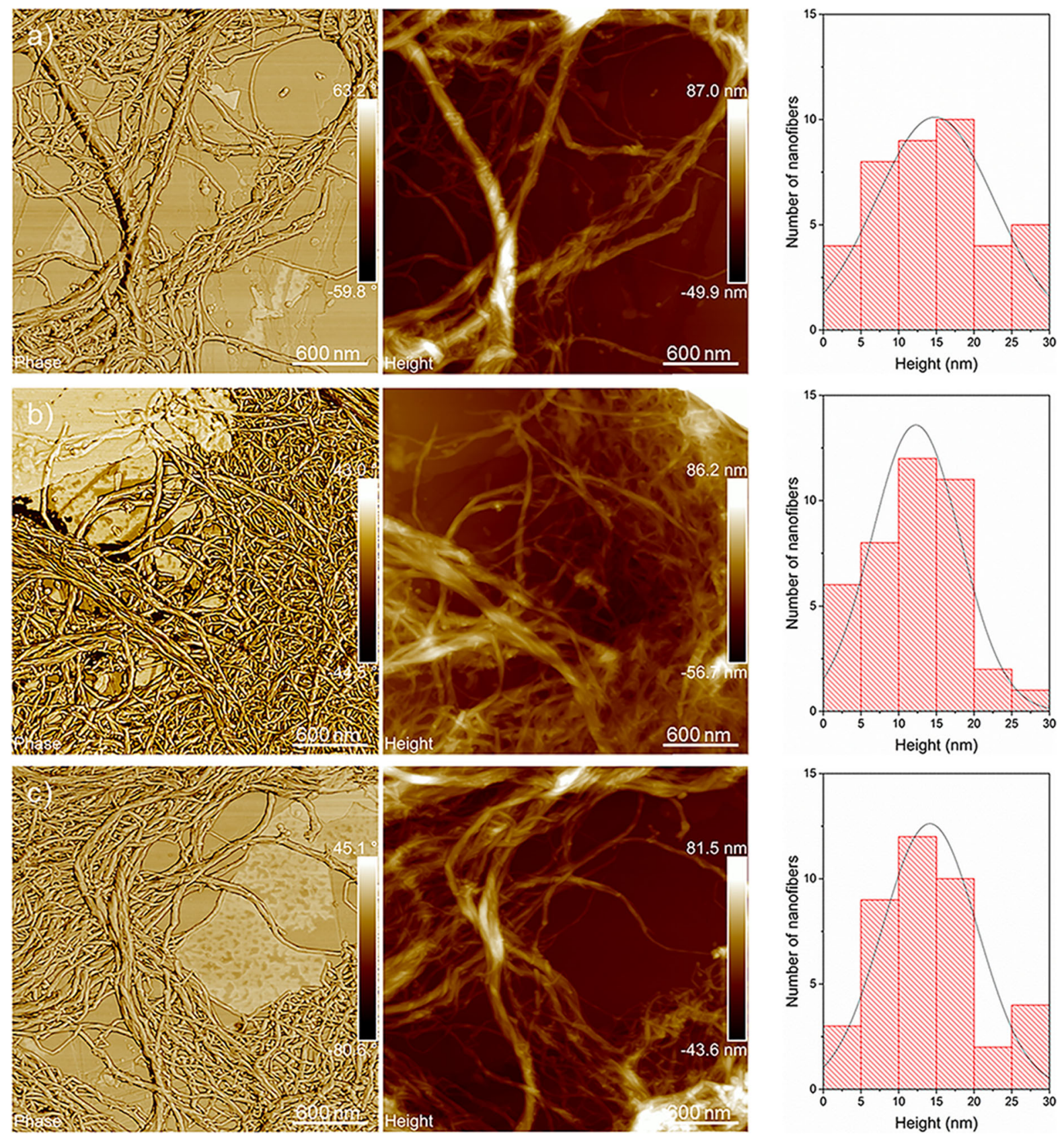

Fig. 5 AFM phase and height images together with the size distribution (from left to right) after fibrillation of a SIL treated-, b bleached SIL-, and c reference nanofibers

Fiber film characteristics

The films obtained before and after the mechanical fibrillation are presented in Fig. 7, and were characterized in terms of density, porosity, morphology, mechanical properties, crystalline structure, topography and wetting behavior.

Large structures were clearly seen in the film from unground SIL treated pulp and the resulting porosity was $53 \mathrm{vol} \%$. It also had a brown color, which we 
Fig. 6 Viscosity as function of the energy consumption during grinding

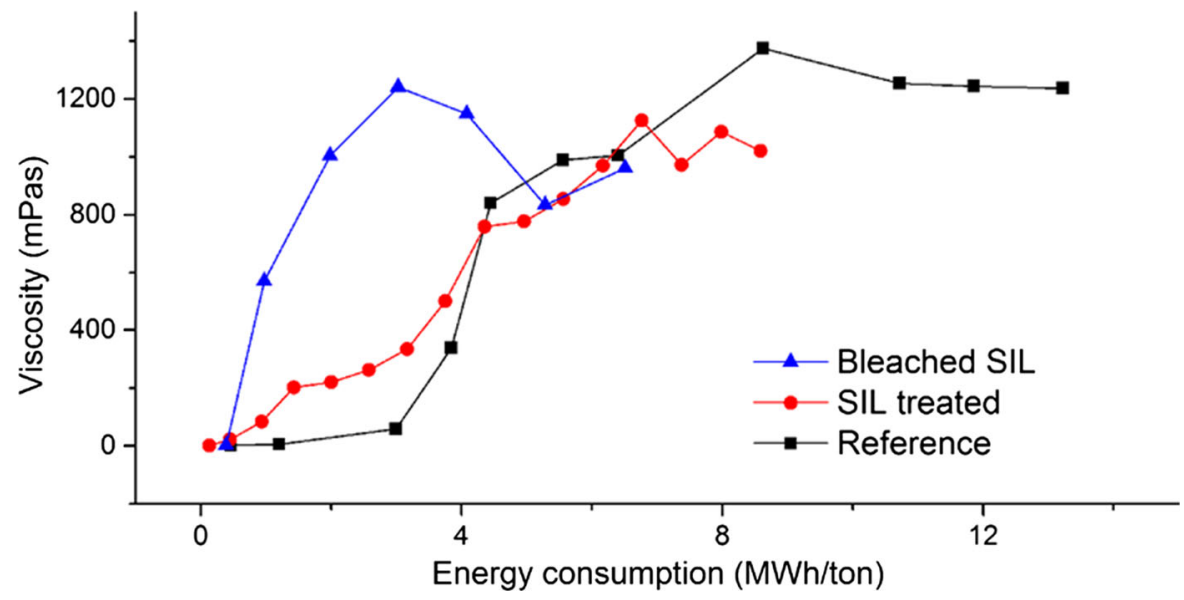

presume was from the remaining lignin in the SIL treated material. After fibrillation, the films of the material decreased in porosity to $21 \mathrm{vol} \%$ as the nanofibers pack closer than the larger microfibers, which was observed by SEM of the film fracture surface. The unground bleached SIL pulp films had a porosity at $46 \mathrm{vol} \%$ and thus lower than is unbleached counterpart. After fibrillation, the bleached SIL film porosity decreased to $19 \mathrm{vol} \%$ which is in similar to both the unbleached and reference nanofiber materials, the latter having a porosity of $59 \mathrm{vol} \%$ of the unground film and a final film porosity of $22 \mathrm{vol} \%$. The slightly lower porosity obtained for the bleached SIL film was consistent with the more transparent appearance of the film. The porosity was decreased by about $70 \mathrm{wt} \%$ for all films upon the fibrillation process and their morphology showed more closely packed layered structures.

The typical stress-strain curves from testing of the films in uniaxial tension before and after the fibrillation process is presented in Fig. 8. Several factors affect the network mechanical properties of the films and one of these is the degree and to some extent the homogeneity of fibrillation (Aitomäki et al. 2015; Sehaqui et al. 2011).

Both SIL treated samples reached a remarkably higher stress region and the bleaching resulted in further improvement of strain-to-failure compared to the reference material. An increase in the mechanical properties could be seen for all the fibrillated wood pulps, associated with the porosity decrease, owing to the smaller fiber dimensions which, in turn, results in the formation of more inter-fiber bonds (Nair et al. 2014) thus giving higher strength wood nanofiber networks. The SIL nanofibers do not reach the strength or strain-to-failure of the bleached materials. The remaining lignin may constitute a barrier for the formation of hydrogen bonds between cellulose molecules, mainly due to its more hydrophobic nature compared to cellulose (Shao and Li 2007), this would thus reduce the inter-fiber bonding and lower the strength for the SIL films. However, the results of the reference material which have nearly equivalent amount of both lignin and hemicellulose do not support this as it displayed a network with $20 \%$ higher strength, and $30 \%$ higher strain-to-failure than the network of SIL nanofibers. This suggests other reasons for reduced inter-fiber bonding in the SIL nanofiber networks such as either the material is less fibrillated or that the residual lignin yielding the brown color has a different effect on the network properties i.e. there is a difference in its surface chemistry compared to the remaining lignin in the reference material. The two possibilities are supported by the results of the bleached SIL nanofibers which displayed a $10 \%$ higher strength and about $20 \%$ increase in the strainto-failure, and has a reduced lignin content of about $60 \mathrm{wt} \%$ compared to the SIL nanofibers and a rapid disintegration of the larger wood structures in the fibrillation process.

The fibrillation occurring upon ultrafine grinding is a result of complex phenomena that are affected by the concentration of the suspensions, gap between the grinding stones (Wang et al. 2012), speed of rotation of the grinding stones (Jonoobi et al. 2012), and the processing time (Nair et al. 2014), all of which contribute to the energy consumption of the process and the quality of the nanofibers. Hence, in terms of 

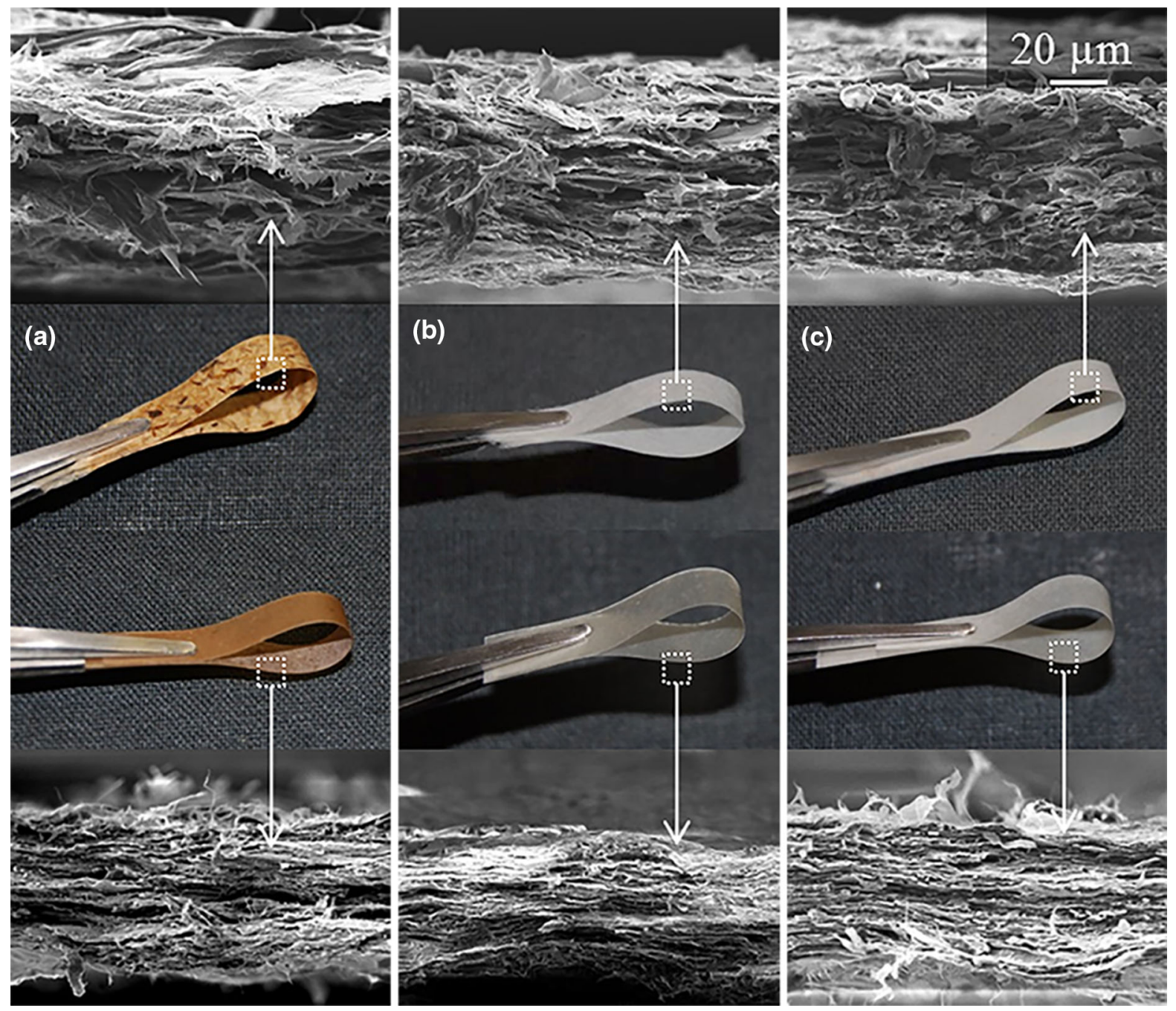

Fig. 7 Photographs and SEM fracture surfaces of the films before (above) and after fibrillation (below) of a SIL treated-, b bleached SIL-, and c reference pulp

Fig. 8 Typical stress-strain curves for the films from a wood pulp, and b nanofibers
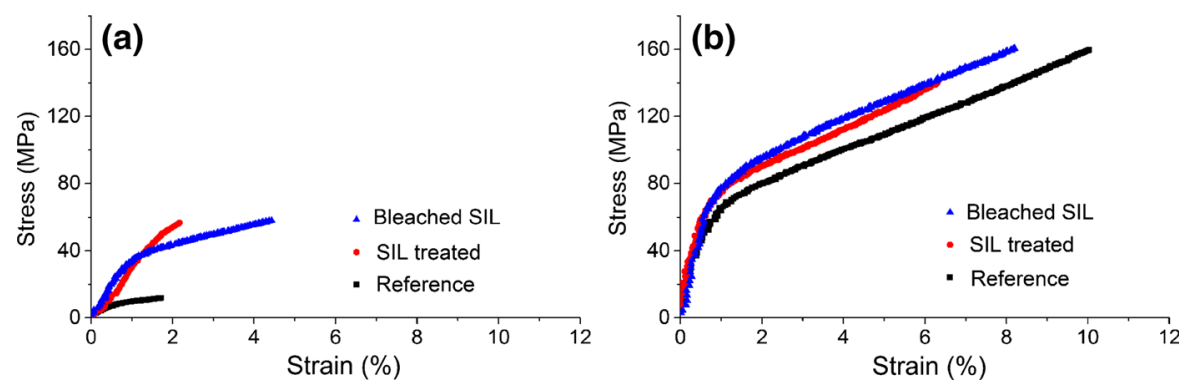

evaluating the efficiency of a process, the strength, stiffness, strain and density at different fibrillation times, was plotted against the energy consumed during the grinding, shown in Fig. 9.
For the fibrillation process of the wood pulps into nanofibers, the amount of energy consumed (see Fig. 9) for the SIL treated pulp was $9 \mathrm{MWh} /$ ton and, after bleaching, the energy consumption was further 
lowered to only $7 \mathrm{MWh} /$ ton. The energy demand for the processing of the reference pulp was measured as $13 \mathrm{MWh} /$ ton. Thus, the bleached SIL pulp could be fibrillated with almost half of the energy demand required for the reference material. In addition, the initial fibrillation appears more efficient for the bleached samples, an observation that may be attributed to the larger structures observed in the non-bleached SIL pulp, which require more energy to be disintegrated.

Interestingly, a more than $20 \%$ higher elastic modulus (Fig. 9b) was obtained in case of the bleached SIL nanofiber network with shortest processing time $(1 \mathrm{~h})$. Furthermore, a plateau appeared to have been reached for strength Fig. 9a, strain Fig. 9c and density Fig. 9d of the bleached SIL films. Nair et al. (2014) observed a similar behaviour of a plateau when grinding bleached softwood; however, this was reached after $4 \mathrm{~h}$ of grinding for strength and strain and $6 \mathrm{~h}$ for the density. A plausibly explanation for the
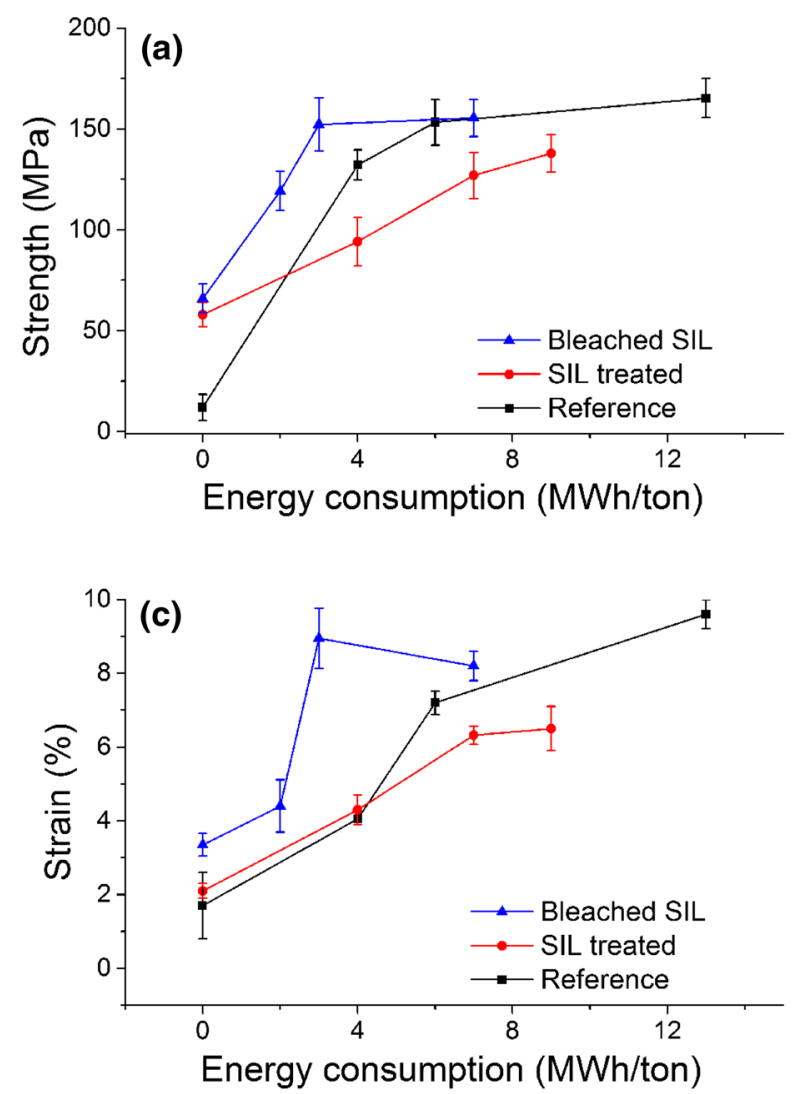

Table 1 The crystallinity index of wood pulp and nanofibers, respectively

\begin{tabular}{lll}
\hline & Wood pulp (\%) & Nanofibers $(\%)$ \\
\hline SIL treated & 87 & 86 \\
Bleached SIL & 85 & 82 \\
Reference & 82 & 80 \\
\hline
\end{tabular}

bleached SIL treated pulp resulting in the most efficient fibrillation is that the large structures remaining in the SIL treated pulp are separated during the bleaching as the remaining lignin is removed, thus enabling a more direct fibrillation in the beginning of the ultrafine grinding process.

In addition to the mechanical properties, the crystalline structure of the films was evaluated before and after the mechanical fibrillation procedure. The crystallinity index (Table 1) was estimated from the X-ray diffraction (XRD) spectra. The diffraction patterns (Online Resource 2) indicated cellulose I
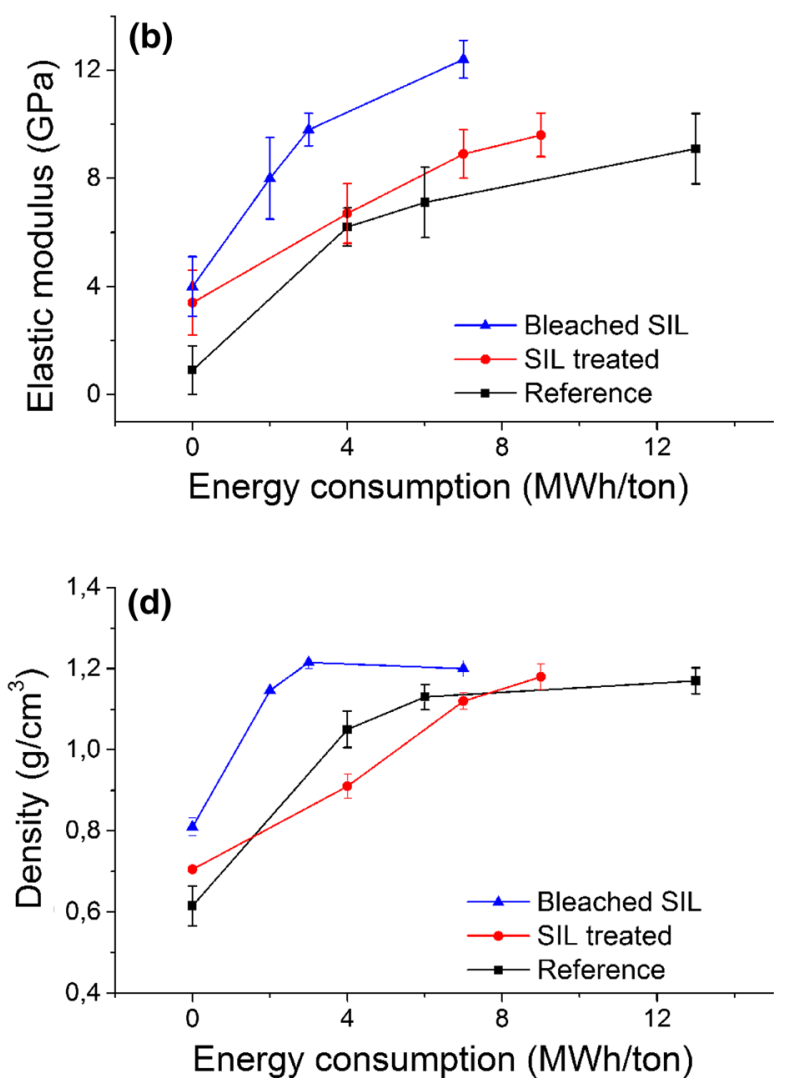

Fig. 9 Mechanical and physical properties of the films at different processing times showing a strength-, b elastic modulus-, c strain-, and $\mathbf{d}$ density as a function of the energy consumption 
Table 2 AFM amplitude images the nanofibers films derived from SIL-, bleached SIL-, and reference pulps

\begin{tabular}{llll}
\hline Nanofiber network & RMS roughness $(\mathrm{nm})$ & Contact angle $\left(^{\circ}\right)$ \\
\hline SIL treated & $81 \pm 5.6$ & $60 \pm 3.0$ \\
Bleached SIL & $59 \pm 10$ & & \\
Reference & & & \\
\hline
\end{tabular}

The root-mean square roughness value and the AFM 3D height images of the surface roughness, and the water contact angle respectively

structure with the characteristic $2 \theta$ diffraction angles close to $14.5^{\circ}, 16.3^{\circ}$ (overlapping peaks) and $22.5^{\circ}$ for all pretreated pulps.

The use of different techniques for the determination of the crystallinity index renders it difficult to compare results with between studies since large variations between the use of different methods and baseline corrections has been shown (Park et al. 2010). Still, the values estimated in this study before and after the fibrillation are slightly lower to values reported, namely 86 and $90 \%$ for wood pulp and nanofibers, respectively, when fibrillated using grinding (Panthapulakkal and Sain 2012). However, it should be noted that the peak height method used in this study for estimation of the crystallinity index has been shown to underestimate the amorphous proportion, hence overestimating the relative amount of crystalline cellulose (Park et al. 2010). For this reason, the crystallinity index values in Table 1 should only be used for comparison between the samples. The results indicate that no dissolution of cellulose occurred during the SIL treatment, displaying cellulose I crystalline structure. The crystallinity index values were comparable to each other further indicating that neither the SIL treatment nor the grinding degrades the crystalline structures of the cellulose nanofibers with the processing conditions used in this study.

Water contact angle measurement was used to evaluate any differences of the nanofiber film surfaces and the results are shown in Table 2 together with the surface root-mean square roughness values obtain from measurements with the AFM.

All the nanofibers showed hydrophilic nature with contact angles lower than $90^{\circ}$. Spence et al. (2010) showed that an increased contact angle value is associated with higher lignin content in wood pulps. Since lignin is less hydrophilic than cellulose, higher contact angles of the wood nanofibers films from SILand reference pulp were expected. The results did indeed follow this behavior and higher contact angles were found for SIL nanofibers and reference nanofibers, namely $60^{\circ}$ and $62^{\circ}$ respectively, compared to $54^{\circ}$ for the bleached SIL nanofibers which has the lowest lignin content. It is also known that the water contact angle correlates with the topographical structure of the surface (Herrera et al. 2014). However, in this case any influence that the surface roughness has on the contact angle cannot be distinguished as significant, when the standard deviations are taken into account. 


\section{Conclusions}

Switchable ionic liquid (SIL) processing was demonstrated as having a high commercial potential for pulping wood prior to mechanical fibrillation into nanofibers.

The SIL treatment drastically reduced the energy demand of obtaining nanofibers with diameters measured below $15 \mathrm{~nm}$ and intact crystalline structures with ultrafine grinding.

Furthermore, the porosity of the films made from the materials decreased by $70 \mathrm{wt} \%$ after fibrillation and an associated increase in the network strength was observed. In addition, a high elastic modulus was shown for the SIL nanofiber films at 9.6 and 12.4 GPa for the bleached SIL films. Bleached SIL nanofiber films have strength matching that of other nanofiber materials from ultrafine grinding. However, SIL nanofiber films were found to have a slightly lower strength.

The reduced energy demand (more than 30\%) was achieved when SIL treated pulp was used compared to the reference pulp upon fibrillation through grinding. Additionally, bleaching reduced the energy consumption a further $16 \%$.

Thus, bleached SIL pulp can yield nanofibers with virtually half the energy consumption compared to the bleached reference pulp, which together with the benign natural of the chemicals and the potential ease of solvent recycling render the commercial operations for the production of nanofibers much more realistic.

Acknowledgments The authors would like to acknowledge the financial support under Bio4Energy-a strategic research environment appointed by the Swedish government, Wallenberg Wood Science Center (WWSC) and Nordic Forest research (SNS) WoodPro.

\section{Compliance with ethical standards}

Conflicts of interest The authors declare that they have no conflict of interest.

Open Access This article is distributed under the terms of the Creative Commons Attribution 4.0 International License (http:// creativecommons.org/licenses/by/4.0/), which permits unrestricted use, distribution, and reproduction in any medium, provided you give appropriate credit to the original author(s) and the source, provide a link to the Creative Commons license, and indicate if changes were made.

\section{References}

Abushammala H, Krossing I, Laboire MP (2015) Ionic liquidmediated technology to produce cellulose nanocrystals directly from wood. Carbohydr Polym 134:609-616

Aitomäki Y, Moreno-Rodriguez S, Lundström S, Oksman K (2015) Vacuum infusion of nanocellulose networks of different porosity. In: Proceedings of the 20th international conference on composite materials, Copenhagen, Denmark

Anugwom I, Mäki-Arvela P, Virtanen P, Damlin P, Sjöholm R, Mikkola JP (2011) Switchable ionic liquids (SILs) based on glycerol and acid gases. RSC Adv 1:452-457

Anugwom I, Mäki-Arvela P, Virtanen P, Willför S, Damlin P, Hedenström M, Mikkola JP (2012a) Treating birch wood with a switchable 1,8-diazabicyclo-[5.4.0]-undec-7-eneglycerol carbonate ionic liquid. Holzforschung 66:809-815

Anugwom I, Mäki-Arvela P, Virtanen P, Willför S, Sjöholm R, Mikkola JP (2012b) Selective extraction of hemicelluloses from spruce using switchable ionic liquids. Carbohydr Polym 87:2005-2011

Anugwom I, Eta V, Mäki-Arvela P, Virtanen P, Hedenström M, Hummel M, Sixta H, Mikkola JP (2014a) Switchable ionic liquids as delignification solvents for lignocellulosic materials. Chemsuschem 7:1170-1176

Anugwom I, Eta V, Mäki-Arvela P, Virtanen P, Hedenström M, Yibo M, Hummel M, Sixta H, Mikkola JP (2014b) Towards optimal selective fractionation for Nordic woody biomass using novel amine-organic superbase derived switchable ionic liquids (SILs). Biomass Bioenergy 70:373-381

Chinga-Carrasco G (2013) Optical methods for the quantification of the fibrillation degree of bleached MFC materials. Micron 48:42-48

D’Andola G, Szarvas L, Massonne K, Stegmann V (2008) Ionic liquids for solubilization of polymers. WO Patent 2008/043837

Eichhorn SJ, Dufresne A, Aranguren M, Marcovich NE, Capadona JR, Rowan SJ et al (2010) Review: current international research into cellulose nanofibres and nanocomposites. Mater Sci 45:1-33

Eta V, Anugwom I, Virtanen P, Eränen K, Mäki-Arvela P, Mikkola JP (2014a) Loop vs. batch reactor setups in the fractionation of birch chips using switchable ionic liquids. Chem Eng J 238:242-248

Eta V, Anugwom I, Virtanen P, Mäki-Arvela P, Mikkola JP (2014b) Enhanced mass transfer upon switchable ionic liquid mediated wood fractionation. Ind Crops Prod 55:109-115

Herrera MA, Mathew AP, Oksman K (2014) Gas permeability and selectivity of cellulose nanocrystals films (layers) deposited by spin coating. Carbohydr Polym 112:494-501

Jessop PG, Heldebrant DJ, Xiaowang L, Eckert CA, Liotta CL (2005) Green chemistry: reversible nonpolar-to-polar solvent. Nature 436:1102

Jonoobi M, Mathew AP, Oksman K (2012) Producing low-cost cellulose nanofiber from sludge as new source of raw materials. Ind Crops Prod 40:232-238

Lahtinen P, Liukkonen S, Pere J, Sneck A, Kangas H (2014) A comparative study of fibrillated fibers from different 
mechanical and chemical pulps. BioResources 9: 2115-2127

Larsson PT, Hult EL, Wickholm K, Pettersson E, Iversen T (1999) CP/MAS 13C-NMR spectroscopy applied to structure and interaction studies on cellulose I. Solid State Nucl Magn Reson 15:31-40

Liitiä T, Maunu SL, Hortling B, Tamminen T, Pekkala O, Varhimo A (2003) Cellulose crystallinity and ordering of hemicelluloses in pine and birch pulps as revealed by solidstate NMR spectroscopic methods. Cellulose 10:307-316

Nair SS, Zhu JY, Deng Y, Ragauskas AJ (2014) Characterization of cellulose nanofibrillation by micro grinding. J Nanopart Res 16:2349-2359

Pang Z, Dong C, Pan X (2016) Enhanced deconstruction and dissolution of lignocellulosic biomass in ionic liquid at high water content by lithium chloride. Cellulose 23: 323-338

Panthapulakkal S, Sain M (2012) Preparation and characterization of cellulose nanofibril films from wood fibre and their thermoplastic polycarbonate composites. Int J Polym Sci 2012:1-6

Park S, Baker J, Himmel M, Parilla P, Johnson D (2010) Cellulose crystallinity index: measurement techniques and their impact on interpreting cellulase performance. Biotechnol Biofuels 3:1-10

Schwanninger M, Hinterstoisser B (2002) Klason lignin: modifications to improve the precision of the standardized determination. Holzforschung 56:161-166

Segal L, Creely JJ, Martin AE, Conrad CM (1959) An empirical method for estimating the degree of crystallinity of native cellulose using the X-ray diffractometer. Text Res J 29:786-794

Sehaqui H, Zhou Q, Ikkala O, Berglund LA (2011) Strong and tough cellulose nanopaper with high specific surface area and porosity. Biomacromol 12:3638-3644
Selkälä T, Sirviö JA, Lorite GS, Liimatainen H (2016) Anionically stabilized cellulose nanofibrils through succinylation pretreatment in urea-lithium chloride deep eutectic solvent. Chemsuschem 9:3074-3083

Shao Z, Li K (2007) The effect of fiber surface lignin on interfibrer bonding. J Wood Chem Technol 26:231-244

Sonneveld EJ, Visser JW (1975) Automatic collection of powder data from photographs. J Appl Crystallogr 8:1-7

Spence KL, Venditti RA, Rojas OJ, Habibi Y, Pawlak JJ (2010) The effect of chemical composition on microfibrillar cellulose films from wood pulps: water interactions and physical properties for packaging applications. Cellulose 17:835-848

Spence KL, Venditti RA, Rojas OJ, Habibi Y, Pawlak JJ (2011) A comparative study of energy consumption and physical properties of microfibrillated cellulose produced by different processing methods. Cellulose 18:1097-1111

Sundberg A, Sundberg K, Lillandt C, Holmbom B (1996) Determination of hemicelluloses and pectins in wood and pulp fibres by acid methanolysis and gas chromatography. Nord Pulp Pap Res J 11:216-219

Swatloski RP, Spear SK, Holbrey JD, Rogers RD (2002) Dissolution of cellulose [correction of cellose] with ionic liquids. J Am Chem Soc 124:4974-4975

Varanasi S, Shall AC, Dado P A, Anderson J, Rao K, Paripati P (2008) Biomass pretreatment. WO Patent 2008/11291A2

Wang QQ, Zhu JY, Gleisner R, Kuster TA, Baxa U, McNeil SE (2012) Morphological development of cellulose fibrils of a bleached eucalyptus pulp by mechanical fibrillation. Cellulose 19:1631-1643

Wasserscheid P, Welton T (2006) Ionic liquids in synthesis. Wiley, Weinheim

Willför S, Sundberg A, Pranovich A, Holmbom B (2005) Polysaccharides in some industrially important hardwood species. Wood Sci Technol 39:601-661 